\title{
Ontogênese, anatomia e ultra-estrutura dos nectários extraflorais de Hymenaea stigonocarpa Mart. ex Hayne (Fabaceae - Caesalpinioideae) ${ }^{1}$
}

\author{
Élder Antônio Sousa Paiva ${ }^{2,4}$ e Silvia Rodrigues Machado ${ }^{3}$
}

Recebido em 1/03/2004. Aceito em 7/11/2005

\begin{abstract}
RESUMO - (Ontogênese, anatomia e ultra-estrutura dos nectários extraflorais de Hymenaea stigonocarpa Mart. ex Hayne (Fabaceae Caesalpinioideae)). O jatobá-do-cerrado (Hymenaea stigonocarpa Mart. ex Hayne) apresenta nectários extraflorais (NEFs), os quais são descritos pela primeira vez no gênero. Neste trabalho foram estudadas a distribuição, ontogênese, estrutura e ultra-estrutura dos nectários extraflorais (NEFs). Amostras de folhas em várias fases de desenvolvimento foram coletadas, fixadas e processadas para estudos em microscopia de luz e eletrônica de transmissão e varredura, segundo técnicas convencionais. Testes histoquímicos foram empregados para determinar a natureza química da secreção. Os NEFs estão distribuídos por todo o limbo, sendo mais concentrados nos terços basal e médio de cada folíolo. Estes nectários são embutidos no mesofilo, apresentam tecido secretor envolvido por uma endoderme e são vascularizados por xilema e floema. A atividade secretora dos NEFs é limitada à fase juvenil da folha. Nas folhas mais velhas, os NEFs tornam-se não funcionais. O tecido secretor dos NEFs é formado a partir da protoderme, enquanto a endoderme tem origem no meristema fundamental. No tecido secretor de nectários funcionais as células apresentam citoplasma denso, núcleo volumoso, mitocôndrias, plastídios com sistema de membranas pouco desenvolvido, gotas de óleo dispersas no citosol, dictiossomos e segmentos de retículo endoplasmático liso. A secreção é liberada por meio de rupturas cuticulares e apresenta polissacarídeos e lipídios.
\end{abstract}

Palavras-chave: cerrado, nectário, secreção, ultra-estrutura

\begin{abstract}
Ontogenesis, anatomy, and ultrastructure of Hymenaea stigonocarpa Mart. ex Hayne (Fabaceae - Caesalpinioideae) extrafloral nectaries). Hymenaea stigonocarpa Mart. ex Hayne, known as "jatobá-do-cerrado" has extrafloral nectaries (EFNs), which are reported for the first time in Hymenaea genus. In this research the origin, distribution, structure, and ultrastructure of the EFNs were studied. Samples of leaflets at different developmental stages were collected, fixed and processed by standard methods for analyses at light and electronic microscopes; histochemical tests were employed to determine the nature of secretion products. EFNs are distributed all over leaf blade, more concentrated on the basal and medial thirds of each leaflet. These nectaries are embedded in the mesophyll, show secretory tissue surrounded by an endodermis, and are vascularized by xylem and phloem. EFN secretory activity was exclusively observed in young leaves. The protoderm origins the EFN secretory tissue, the ground meristem originates the endodermis and the procambium originates the vascular tissues. Secretory cells of functional EFNs showed dense cytoplasm, large nucleus, mitochondria, plastids with a poorly developed membrane system, oil drops scattered in the cytosol, dictyosome, and smooth endoplasmic reticulum segments. Secretion was released by cuticle rupture and contains polysaccharides and lipids.
\end{abstract}

Key words: cerrado vegetation, nectary, secretion, ultrastructure

\section{Introdução}

Hymenaea stigonocarpa Mart. ex Hayne, o jatobá-do-cerrado, apresenta distribuição homogênea e ocorre, predominantemente, em áreas de cerrado (Lee \& Langenheim 1975), sendo uma espécie lenhosa típica deste bioma. São escassos os estudos anatômicos das espécies de Hymenaea, destacando-se aqueles destinados à análise estrutural das cavidades secretoras de resina (Lee \& Langenheim 1975) e ao estudo anatômico dos órgãos vegetativos (Camargo 1960).

Os nectários extraflorais (NEFs) podem ser definidos como glândulas que produzem uma secreção na qual predominam açúcares e são encontrados nos órgãos vegetativos (Durkee 1982). A grande variabilidade estrutural dos NEFs, bem como sua ampla ocorrência em vários táxons tem sido destacada nas revisões de vários autores (Schnell et al. 1963; Elias 1983; Oliveira \& Leitão Filho 1987; Koptur 1992; Blüthgen \& Reifenrath 2003). O número de famílias

\footnotetext{
1 Parte da Tese de Doutorado do primeiro Autor

2 Universidade Federal de Minas Gerais, Instituto de Ciências Biológicas, Departamento de Botânica, CEP 31270-901, Belo Horizonte, MG, Brasil

3 Universidade Estadual Paulista Júlio de Mesquita Filho, Instituto de Biociências, Departamento de Botânica, C. Postal 510, CEP 18618-000, Botucatu, SP, Brasil

4 Autor para correspondência: epaiva@icb.ufmg.br
} 
de Angiospermas portadoras de NEFs é superior a 90 (Blüthgen \& Reifenrath 2003), sendo que a flora tropical possui um grande número de táxons com NEFs, os quais são mais abundantes nas comunidades tropicais que nas temperadas (Oliveira et al. 1999). Estudos recentes revelam a ampla distribuição dos NEFs na vegetação lenhosa do cerrado (Oliveira \& Pie 1998).

São diversos os relatos de que os NEFs estão envolvidos na proteção contra a herbivoria (Vesprini et al. 2003; Oliveira \& Freitas 2004). A proteção contra a ação de diversos herbívoros depende, algumas vezes, da associação benéfica entre plantas e formigas, sendo estas atraídas pelos produtos dos NEFs (Koptur et al. 1998; Oliveira \& Freitas 2004).

Na família Fabaceae os NEFs estão presentes na maioria dos membros da subfamília Mimosoideae, sendo comuns nas Caesalpinioideae e, com menor frequiência, nas Faboideae (Elias 1983). Nas Fabaceae do cerrado, os NEFs são mais freqüentes entre os membros da subfamília Mimosoideae, conforme sugerem Oliveira \& Leitão Filho (1987) embora, segundo Paiva et al. (2001), a presença de plantas portadoras de NEFs neste bioma seja subestimada.

Apesar de o cerrado ser rico em espécies portadoras de NEFs (Oliveira et al. 1995), poucos são os estudos estruturais e histoquímicos destes nectários. Tais estudos são importantes para a compreensão da biologia da secreção e, sobretudo, das interações entre estas estruturas e o ambiente. Neste artigo são descritas a localização, ontogênese, anatomia e a ultraestrutura dos NEFs de Hymenaea stigonocarpa Mart. ex Hayne, com informações sobre a distribuição temporal da atividade secretora.

\section{Material e métodos}

Amostras do limbo foliolar de Hymenaea stigonocarpa Mart. ex Hayne foram coletadas em diferentes fases de desenvolvimento, em exemplares adultos ocorrentes em cerrado no município de Botucatu, SP. Ramos férteis foram depositados no herbário do Departamento de Botânica, Instituto de Biociências de Botucatu, Universidade Estadual Paulista (BOTU) sob os números 23189-23191, 23132 e 23133.

Para a determinação da densidade de NEFs $\left(\mathrm{NEF} / \mathrm{cm}^{2}\right)$ foram amostradas 50 folhas em cada indivíduo estudado, das quais determinou-se a área do limbo e o número de nectários. Os resultados obtidos foram submetidos à análise de variância e as médias comparadas pelo teste de Tukey (5\%).

Para microscopia de luz as amostras foram fixadas em mistura de Karnovsky (Karnovsky 1965) por 24 h, desidratadas em série etílica e incluídas em resina hidroxi-etil-metacrilato (Leica). Cortes transversais e paradérmicos $(5 \mu \mathrm{m})$ foram obtidos em micrótomo e corados em Azul de Toluidina 0,05\%, pH 4.3 (O'Brien et al. 1964). Os seguintes testes histoquímicos foram empregados: solução aquosa de vermelho de rutênio para detecção de polissacarídeos ácidos, cloreto férrico para compostos fenólicos, floroglucinol ácido para lignina (Johansen 1940); Sudan black B para lipídios (Pearse 1980); azul de bromofenol para proteínas (Mazia et al. 1953); reagente de Schiff (PAS) para polissacarídeos; reagente de Fehling para açúcares redutores (Sass 1951) e safranina aquosa (1\%) para detectar caminhos apoplásticos (Seago et al. 2000).

Para microscopia eletrônica de transmissão as amostras foram fixadas em mistura de Karnovsky (Karnovsky 1965) por 24 h, pós-fixadas em tetróxido de ósmio (1\%, tampão fosfato $0.1 \mathrm{M}, \mathrm{pH} 7.2) \mathrm{e}$ processadas segundo métodos usuais (Roland 1978). As secções ultra-finas foram contrastadas com acetato de uranila e citrato de chumbo e examinadas em microscópio de transmissão Philips CM 100 a 60 KV.

Para observação ao microscópio eletrônico de varredura as amostras foram fixadas em glutaraldeído a 2,5\% (tampão fosfato $0.1 \mathrm{M}, \mathrm{pH} 7.2$ ), desidratadas em serie etílica, submetidas à secagem ao ponto crítico e metalizadas com ouro (Robards 1978). As amostras foram examinadas ao microscópio eletrônico de varredura modelo Philips 515.

\section{Resultados}

Localização e distribuição temporal da atividade secretora - Os nectários extraflorais (NEFs) distribuem-se por todo o limbo dos folíolos, não havendo simetria quanto à distribuição destes no par de folíolos que compõem cada folha. Nas regiões basal e mediana, onde ocorrem em maior número, não há diferença significativa quanto à densidade $\left(\mathrm{NEF} / \mathrm{cm}^{2}\right)($ Fig. 1). Na porção apical do limbo, contudo, a densidade de NEFs é significativamente menor (Fig. 1).

Em Hymenaea stigonocarpa Mart. ex Hayne as folhas ainda não expandidas apresentam coloração avermelhada; a presença de um halo de coloração verde nas imediações dos NEFs facilita a visualização destes (Fig. 1), sobretudo na face abaxial, onde ocorre a liberação do néctar. Este halo clorofilado contrasta com as demais regiões do mesofilo, as quais são 
aclorofiladas nesta fase de desenvolvimento das folhas.

Nas folhas adultas, o halo formado pelo parênquima clorofiliano desaparece, uma vez que as demais regiões do mesofilo tornam-se fotossintetizantes e os NEFs tornam-se pouco perceptíveis, além de estarem inativos.

Anatomia e histoquímica - Os NEFs de Hymenaea stigonocarpa Mart. ex Hayne são embutidos no mesofilo foliolar, estando o tecido secretor localizado na face abaxial, entre os tecidos vasculares e a epiderme (Fig. 3).

As células do tecido secretor são globosas, pequenas, com paredes celulares delgadas e citoplasma denso (Fig. 2-4). Os espaços intercelulares são mais desenvolvidos na porção voltada para a epiderme, na face abaxial (Fig. 4).

Uma camada de células interna ao tecido secretor estabelece uma linha divisória entre este e as demais regiões da folha. Esta camada, uma endoderme típica, apresenta células dispostas de modo compacto, paredes celulósicas impregnadas por lignina e suberina e citoplasma pouco denso, o que as torna distintas daquelas do tecido secretor (Fig. 3). A endoderme confere isolamento apoplástico ao tecido secretor do NEF, conforme demonstrado mediante o emprego de safranina, utilizada para determinar a permeabilidade apoplástica.

Na superfície abaxial, pólo secretor do NEF, a epiderme apresenta células globosas, com paredes delgadas e vacuoma desenvolvido. Entre estas células há espaços amplos (Fig. 4, 11), através dos quais ocorre a passagem do néctar. Este se acumula sob a cutícula, sendo que na fase secretora forma-se um amplo espaço subcuticular. A cutícula, nesta região, é mais delgada que no restante da folha.

O nectário, na face abaxial, é delimitado por uma elevação em forma de aréola. $\mathrm{Na}$ aréola, as células epidérmicas apresentam paredes espessas e lignificadas. Em alguns casos, a camada subepidérmica torna-se esclerificada, reforçando a aréola (Fig. 3, 11).

Os NEFs são vascularizados por xilema e floema. Cortes paradérmicos mostraram que os tecidos vasculares dispõem-se radialmente ao tecido secretor, não atingindo as células secretoras (Fig. 2, 3, 11).

As células parenquimáticas do floema, adjacentes aos NEFs, apresentam numerosos cristais prismáticos de oxalato de cálcio (Fig. 5). Estes cristais assemelhamse a outros encontrados nas imediações dos tecidos vasculares da folha.

No pólo secretor, que se apresenta como uma depressão, observou-se acúmulo de óleo nos espaços intercelulares e no espaço subcuticular. A presença de polissacarídeos solúveis no protoplasto das células secretoras é pouco expressiva na fase pré-secretora, sendo intensa na fase secretora. Grãos de amido são pouco freqüentes nas células secretoras dos NEFs, entretanto, são abundantes nos cloroplastos das células em paliçada do mesofilo. Amostras do néctar, submetidas à hidrólise ácida, foram tratadas com reagente de Fehling, detectando-se a presença de açúcares não redutores. Compostos fenólicos estão presentes na endoderme e no tecido secretor, sobretudo na fase pós-secretora. Estes compostos são abundantes, também, na epiderme e no mesofilo.

Origem e desenvolvimento - Primórdios foliares, em cortes transversais da gema apical, apresentam protoderme, uma camada de meristema fundamental em cada uma das faces do limbo e o procâmbio disposto na região central (Fig. 6).

$\mathrm{Na}$ protoderme, as células iniciais do tecido secretor do NEF apresentam alta densidade citoplasmática e ausência de compostos fenólicos, o que as torna distintas das demais. Estas células dividem-se no plano periclinal, produzindo um segundo estrato, o qual se divide repetidas vezes, em planos diversos (Fig. 7-10), dando origem ao tecido secretor. A partir do procâmbio, forma-se o sistema vascular que abastece o NEF. Na face abaxial, as células do meristema fundamental, dispostas entre a protoderme e o procâmbio, sofrem divisões anticlinais e obliquas, originando a camada limítrofe do tecido secretor.

A formação do NEF é rápida e acompanhada de expressiva expansão celular. Os NEFs diferenciamse em folhas muito jovens e iniciam a atividade secretora tão logo as folhas encontrem-se liberadas da cápsula formada pelo par de estípulas.

Nas folhas não expandidas os NEFs são fortemente projetados para a face abaxial (Fig. 10). Com o processo de expansão e conseqüente aumento da espessura do mesofilo, esta diferença se reduz e a região do NEF passa a apresentar praticamente a mesma espessura do restante do limbo (Fig. 11).

Caracterização ultra-estrutural - Na face adaxial do limbo de folhas adultas, os NEFs são visíveis como pequenas elevações nas quais a densidade de tricomas é maior (Fig. 12). Na face abaxial, os NEFs apresentam-se como estruturas circulares, de bordo elevado e leve depressão central; a aréola que delimita o pólo secretor apresenta, aproximadamente, $400 \mu \mathrm{m}$ de diâmetro (Fig. 13-14). No pólo secretor 

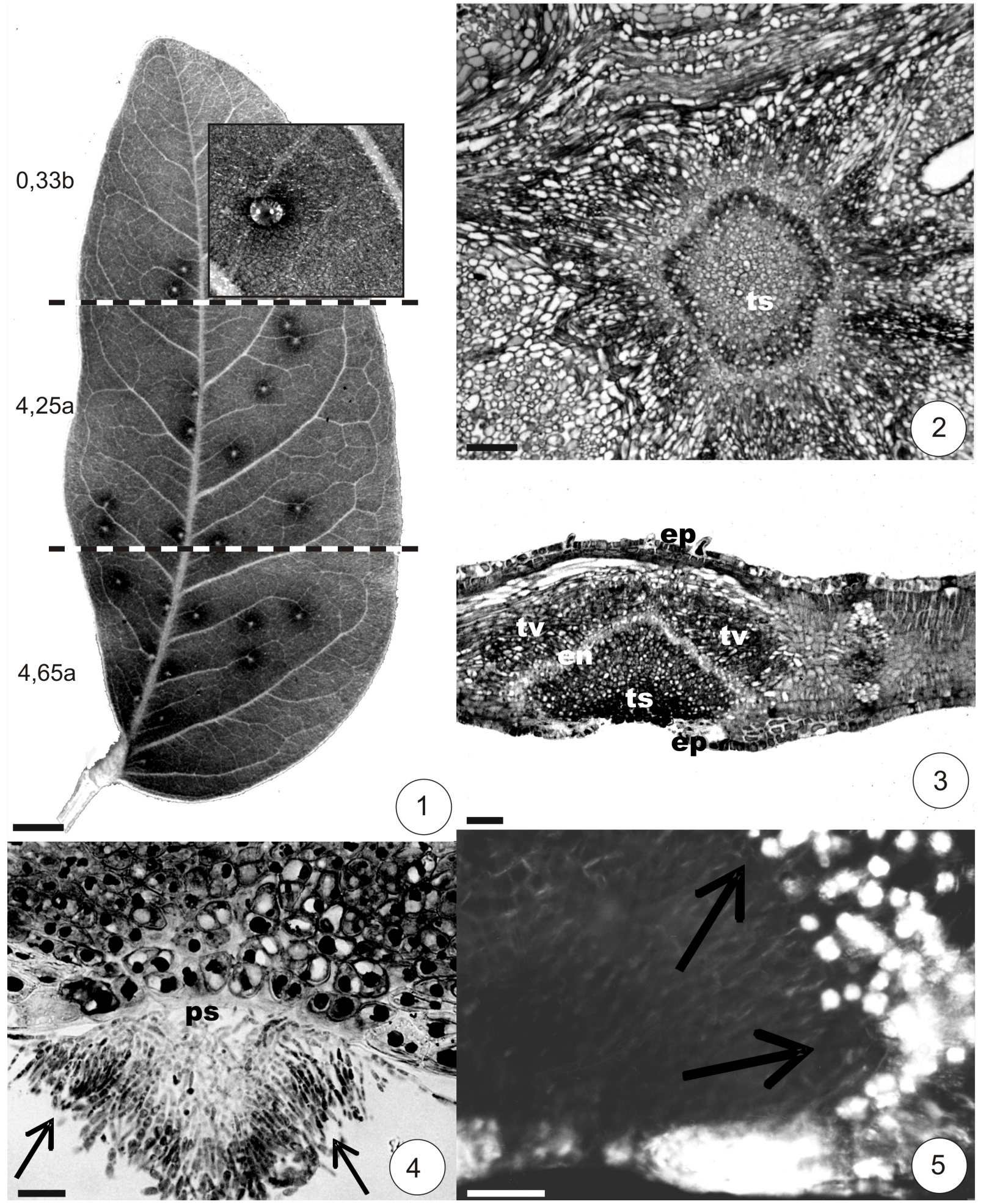

Figuras 1-5. Nectários extraflorais em H. stigonocarpa Mart. ex Hayne. 1. Face adaxial de folha jovem, mostrando nectários extraflorais. Notar o halo formado pelo parênquima clorofiliano e, no detalhe, face abaxial mostrando liberação do néctar. As médias representam a densidade de nectários extraflorais, médias seguidas de mesma letra são estatisticamente iguais (Tukey, 0,05). 2. Corte paradérmico mediano na região do nectário extrafloral já diferenciado; setas indicam a posição da endoderme. Notar a intensa vascularização e o tecido secretor (ts). 3. Vista geral de nectário extrafloral em corte transversal do folíolo, mostrando tecidos vasculares (tv), endoderme (en), tecido secretor (ts) e epiderme (ep). 4. Detalhe do pólo secretor (ps) do nectário extrafloral ao término da fase secretora, notar a presença de hifas (setas). 5. Detalhe do nectário extrafloral em corte transversal, sob luz polarizada. Notar a quantidade de cristais de oxalato de cálcio na região dos tecidos vasculares, as setas indicam a posição da endoderme. Barras: $1=1 \mathrm{~cm} ; 2-3=100 \mu \mathrm{m} ; 4=25 \mu \mathrm{m} ; 5=50 \mu \mathrm{m}$. 


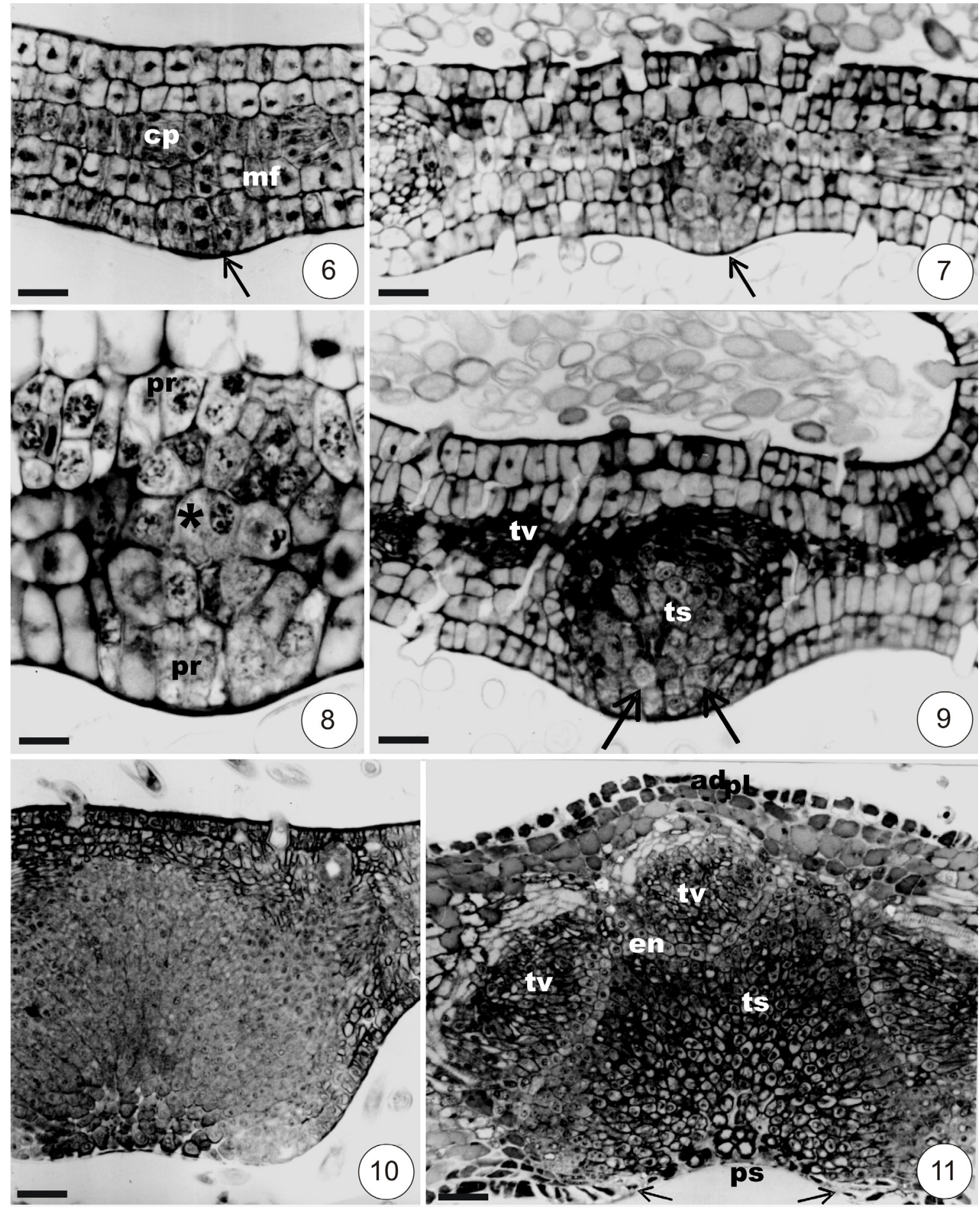

Figuras 6-11. Cortes transversais de folhas de H. stigonocarpa Mart. ex Hayne em diferentes etapas do desenvolvimento, na região do nectário extrafloral. 6. Primórdio foliar. Notar as células resultantes da primeira divisão periclinal das iniciais protodérmicas (seta); o cordão procambial (cp) no centro e as duas camadas do meristema fundamental (mf). 7. Fase posterior, mostrando o início da formação do tecido secretor e a protuberância (seta) correspondente ao futuro nectário extrafloral. 8. Detalhe mostrando o cordão procambial (cp), células resultantes das primeiras divisões da protoderme (*) e a protoderme (pr) na face abaxial. 9. Notar tecidos vasculares (tv) já diferenciados, tecido secretor evidente (ts) e a continuidade das divisões periclinais na protoderme (setas). 10. Nectário extrafloral já formado, em folha recém liberada do par de estípulas. Notar largura maior na região do nectário extrafloral em relação ao restante do limbo. Notar o grande volume do tecido secretor. 11. Nectário extrafloral em folha expandida. Notar a epiderme adaxial (ad), tecido vascular (tv), endoderme (en), tecido secretor (ts) e, na face abaxial a epiderme com esclereides (setas) nos bordos do pólo secretor (ps). Barra: 6-7 e $9=25 \mu \mathrm{m} ; 8=10 \mu \mathrm{m} ; 10-11=50 \mu \mathrm{m}$. 
os estômatos estão ausentes, entretanto, rupturas na cutícula são freqüentes (Fig. 14).

Ao microscópio eletrônico de transmissão, foram estudadas três fases de desenvolvimento dos NEFs: pré-secretora, secretora e pós-secretora.

$\mathrm{Na}$ fase pré-secretora, as células do tecido secretor apresentam citoplasma denso. O núcleo é conspícuo, volumoso, com nucléolo evidente (Fig. 15). $\mathrm{O}$ retículo endoplasmático liso (REL) forma pilhas dispersas pelo citosol (Fig. 17-18). Há, em algumas regiões do retículo endoplasmático, associação com ribossomos, entretanto, em todas as fases de desenvolvimento dos NEFs, há predomínio do REL.

Gotas de material lipídico ocorrem dispersas no citosol e nas imediações do envelope plastidial (Fig. 18). Os dictiossomos são pouco freqüentes e apresentam número variável de cisternas (Fig. 18-19). Os plastídios são globosos, com membranas pouco desenvolvidas e estroma pouco denso (Fig. 18). As mitocôndrias são abundantes e apresentam cristas pouco desenvolvidas (Fig. 18-19). O vacuoma é formado por vários vacúolos pequenos (Fig. 15). Nota-se, no espaço entre a membrana plasmática e a parede celular, a presença de corpos paramurais (Fig. 16).

$\mathrm{Na}$ fase secretora, as células do tecido secretor apresentam citoplasma denso e núcleo volumoso (Fig. 20) e características ultra-estruturais semelhantes às descritas na fase anterior. Notou-se, entretanto, maior número de dictiossomos (Fig. 21), maior densidade do REL, que forma pilhas dispostas ao redor do núcleo (Fig. 22), além de segmentos dispersos no citosol. Observou-se, ainda, a presença de gotas de óleo no citosol (Fig. 21) e na secreção acumulada nos espaços intercelulares (Fig. 24). São poucos os campos de pontoação primários nos quais plasmodesmos estabelecem contato entre as células secretoras; entretanto, estes são freqüentes entre as células endodérmicas e secretoras (Fig. 23). Esta característica é comum a todas as fases do desenvolvimento dos NEFs. As células epidérmicas apresentam citoplasma reduzido e vacúolo central volumoso, ocupado por compostos fenólicos. Entre estas células, ocorrem espaços amplos nos quais observou-se a presença de secreção (Fig. 24).

Em folhas já diferenciadas, quando os NEFs atingem a fase pós-secretora, as células do tecido secretor apresentam considerável aumento do vacuoma (Fig. 25) e ocorre necrose do tecido secretor e conseqüente inativação do NEF. Nessa região é freqüente a presença de fungos, provavelmente

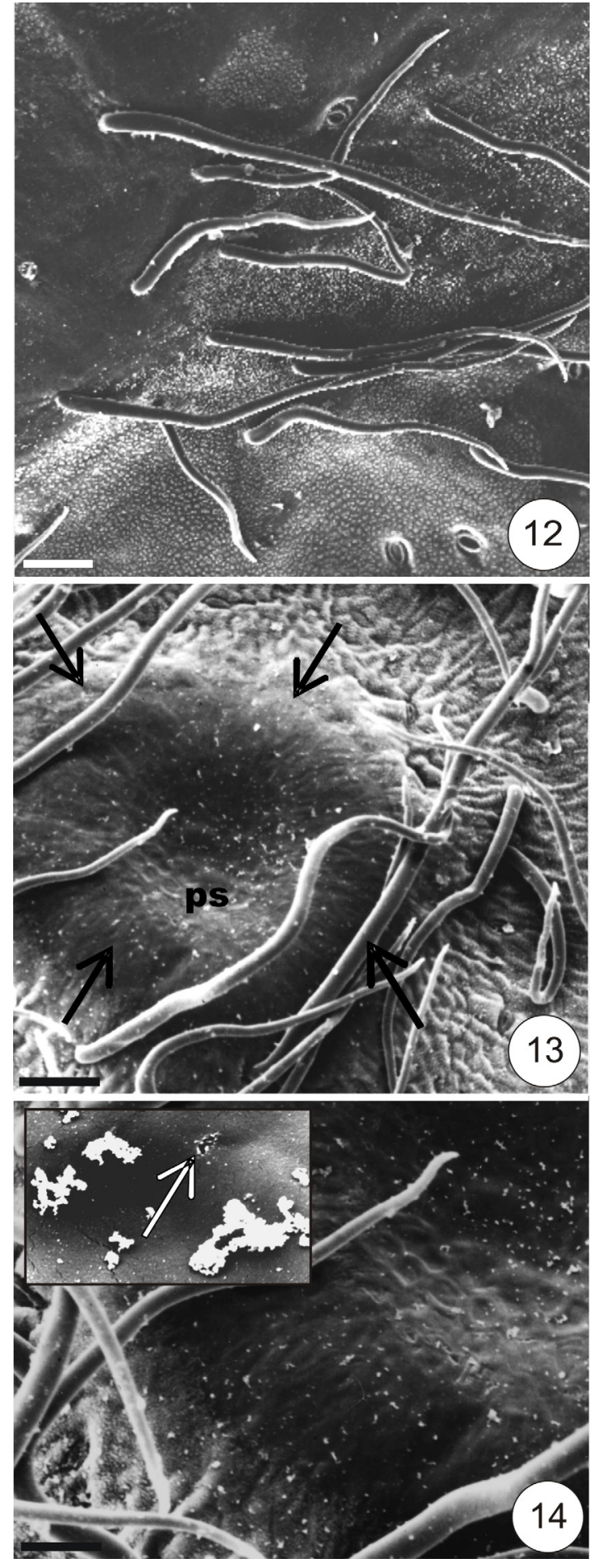

Figuras 12-14. Micromorfologia da superfície foliar de H. stigonocarpa Mart. ex Hayne na região do nectário extrafloral. 12. Detalhe da face adaxial em direção ao nectário extrafloral. Observar que as únicas alterações em relação à região vizinha são uma discreta elevação e maior densidade de tricomas. 13. Vista da face abaxial, setas delimitam o nectário extrafloral. Notar elevação da aréola que o delimita e o pólo secretor em depressão (ps). 14. Detalhe da face abaxial, região do nectário extrafloral. Observar ausência de ceras epicuticulares, tricomas e estômatos na face secretora. Em destaque resíduos de secreção e ruptura na cutícula (seta). Barra: 12-13 = $100 \mu \mathrm{m} ; 14=50 \mu \mathrm{m}$. 

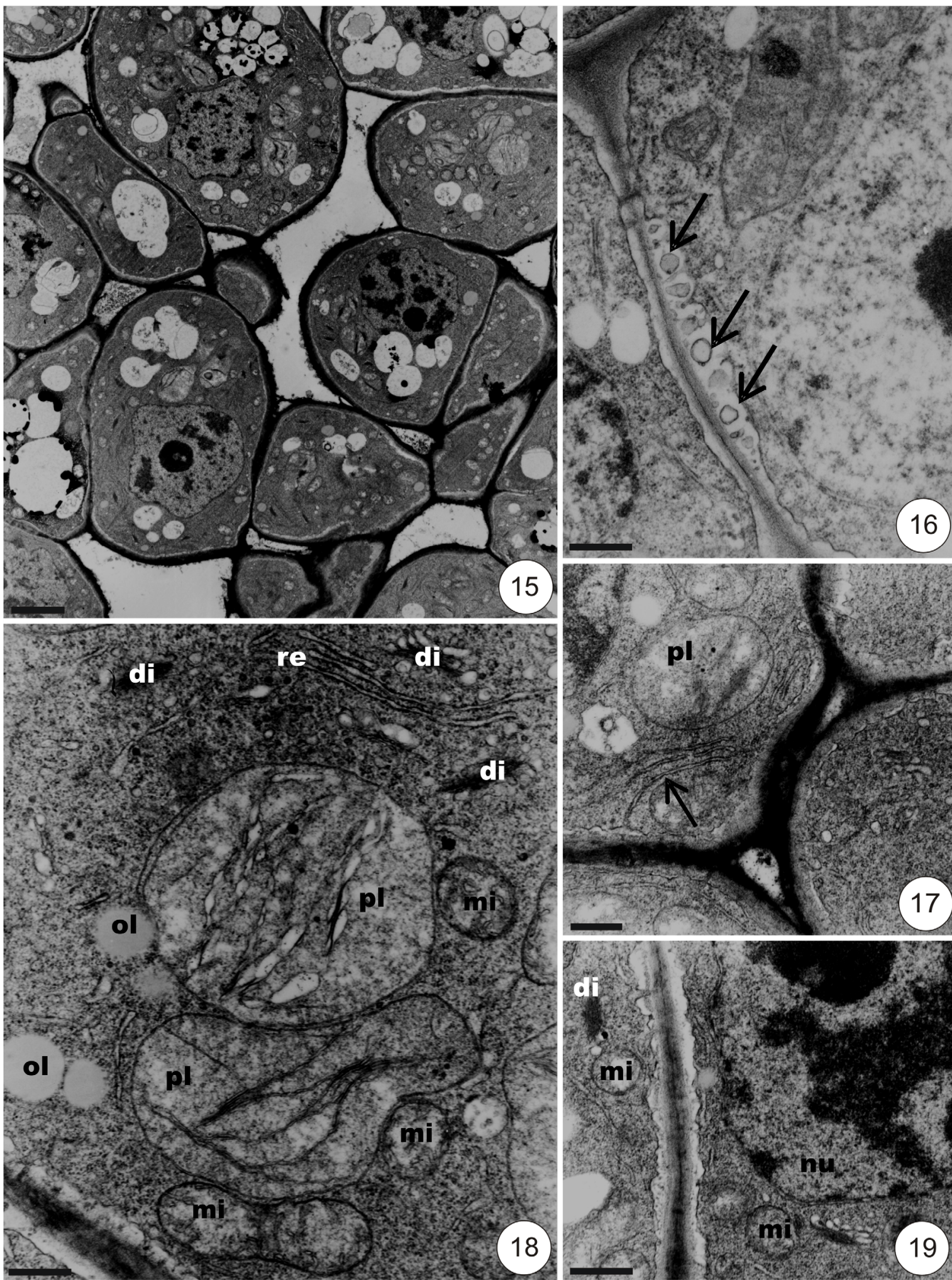

Figuras 15-19. Células secretoras do nectário extrafloral de H. stigonocarpa Mart. ex Hayne, na fase pré-secretora. 15. Vista geral. Notar a densidade citoplasmática, núcleo esférico e volumoso, vacuoma pouco desenvolvido e espaços intercelulares amplos (nas imediações do pólo secretor). 16. Detalhe de célula secretora mostrando a presença de corpos paramurais (setas). 17. Detalhe mostrando plastídio (pl) e a associação entre reticulo endoplasmático e membrana plasmática (seta). 18. Detalhe de célula secretora mostrando plastídios com sistemas de endomembranas pouco desenvolvido (pl); mitocôndrias (mi); gotas de óleo (ol), sendo uma delas associada ao envelope plastidial; segmentos de retículo endoplasmático (re) e dictiossomo (di). 19. Detalhe de célula secretora mostrando núcleo (nu), dictiossomo (di) e mitocôndrias (mi). Barras: $15=3 \mu \mathrm{m} ; 16-18=0,5 \mu \mathrm{m} ; 19=0,3 \mu \mathrm{m}$. 

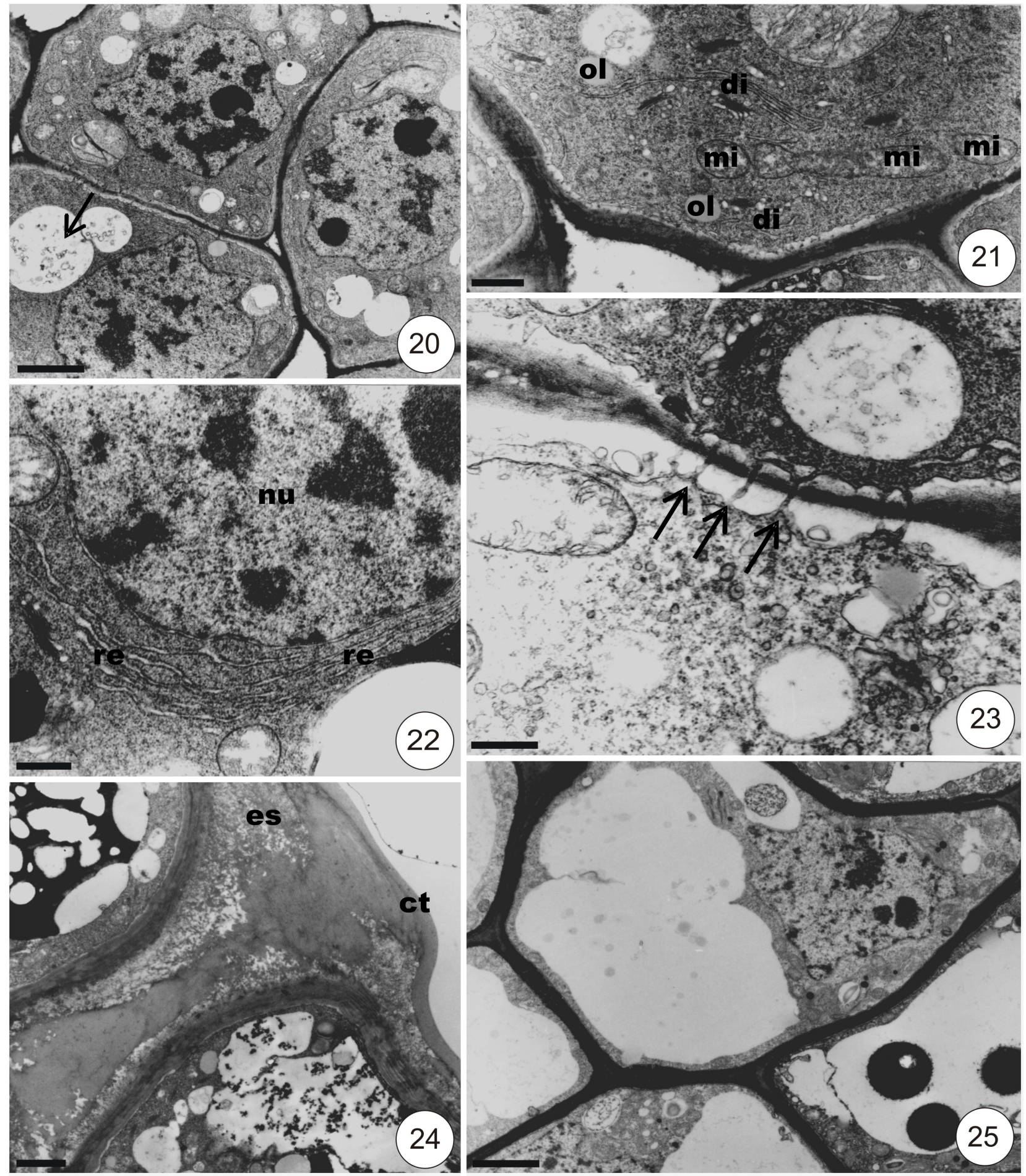

Figuras 20-25. Células secretoras, endoderme e epiderme do nectário extrafloral de $H$. stigonocarpa Mart. ex Hayne, fase secretora e pós-secretora. 20. Células do tecido secretor. Observa-se núcleo volumoso, citoplasma denso, presença de corpos vesiculares no interior dos vacúolos (setas) e plasmodesmos conectando células adjacentes (ponta de seta). 21. Detalhe de célula secretora mostrando gotas de óleo no citosol (ol), mitocôndrias (mi) e dictiossomos (di). 22. Detalhe de célula secretora. Observar núcleo (nu) e continuidade entre envelope nuclear e retículo endoplasmático (re). 23. Detalhe de célula endodérmica (abaixo), notar aspecto vesiculado do citoplasma, mitocôndria e, na parede, a presença de plasmodesmos (setas) estabelecendo contato entre esta e a célula secretora adjacente (acima). 24. Detalhe da epiderme no pólo secretor. Observar vacúolo amplo, central e acúmulo de compostos fenólicos; entre as células há um espaço amplo, formando um canal que permite a liberação da secreção até o espaço subcuticular (es). Notar a presença de secreção neste espaço e espaço subcuticular. A cutícula (ct) mantêm-se integra. 25. Células do tecido secretor em fase pós-secretora, notar aumento do vacuoma e acúmulo de compostos fenólicos no vacúolo. Barra: 20, 24 e $25=2 \mu \mathrm{m} ; 21=1 \mu \mathrm{m} ; 22-23=0,5 \mu \mathrm{m}$. 
saprófitas, os quais ficam restritos à região do tecido secretor, não ultrapassando a barreira imposta pela endoderme; a colonização se dá através do pólo secretor (Fig. 4). Nesta fase, as células endodérmicas apresentavam paredes mais espessas e, aparentemente, maior impregnação por lignina.

\section{Discussão}

Localização e distribuição temporal da atividade secretora - A distribuição preferencial de NEFs na porções basais do limbo foliar, como observado em Hymenaea stigonocarpa Mart. ex Hayne, foi descrita por Elias (1980), em Leonardoxa africana (Baill.) Aubrév. (Fabaceae) e por S.R. Machado (dados não publicados) em Citharexylum mirianthum Cham. (Verbenaceae).

À semelhança do observado em Hymenaea stigonocarpa Mart. ex Hayne, em Catalpa speciosa Warder ex Engelm. (Bignoniaceae), Stephenson (1982) relata que a produção de néctar nas folhas é distribuída por vários nectários. Ainda segundo este autor, em consequiência desta distribuição de NEFs, as formigas patrulham uma extensa porção da folha enquanto buscam por néctar, o que pode resultar em maiores taxas de herbívoros descobertos pelas formigas, aumentando as taxas de predação. Padrão semelhante de distribuição de NEFs é também relatado por Morellato \& Oliveira (1994), em Guarea macrophylla Vahl. (Meliaceae).

O desenvolvimento de nectários na face abaxial das folhas é interpretado, no presente estudo, como uma maneira eficaz para reduzir a perda de néctar por evaporação, aumentando sua disponibilidade para os agentes protetores.

Em Hymenaea stigonocarpa Mart. ex Hayne, observou-se, nos estudos de campo, que a atividade secretora tem início por ocasião da ruptura das estípulas, quando a folha jovem é exposta e estende-se após a completa expansão da folha. Este padrão de funcionalidade é freqüente em NEFs e foi observado também em outros gêneros de Fabaceae (Elias 1972; 1980; Paiva et al. 2001) assim como em outras famílias (Elias et al. 1975; Durkee 1982; Morellato \& Oliveira 1994).

Em Pithecellobium macradenium Pittier (Fabaceae), Elias (1972) observou que NEFs foliares tornam-se inativos em folhas velhas, o que leva este autor a supor que o encerramento da atividade secretora dos NEFs esteja associado ao fim da vida útil da folha. Nossos resultados mostram que o encerramento da atividade secretora dos NEFs de Hymenaea stigonocarpa Mart. ex Hayne ocorre tão logo a folha esteja madura, sendo que estas folhas permanecem na planta por um ano, não havendo, portanto, relação entre a atividade dos NEFs e a vida útil da folha, nesta espécie.

A presença de cloroplastos nas proximidades do NEF é aqui interpretada como indício da participação dessas organelas na elaboração dos precursores do néctar, o que possibilita fornecer recompensa para insetos benéficos no estágio de maior suscetibilidade das folhas. Deve-se ressaltar que nessa fase os cloroplastos estão indiferenciados nas demais regiões do mesofilo, os quais mostram-se aclorofilados. Para Koptur (1992) a coloração apresentada por alguns NEFs pode constituir um auxílio visual para a localização destas estruturas pelos animais, o que não pode ser descartado no caso dos NEFs de Hymenaea stigonocarpa Mart. ex Hayne.

Anatomia e histoquímica - Os NEFs das Angiospermas foram classificados por Zimmermann (1932) considerando a estrutura e localização desses. Entretanto, os NEFs presentes em Hymenaea stigonocarpa Mart. ex Hayne não se enquadram em nenhum dos tipos propostos nesse sistema. Elias (1980) propõe uma categoria adicional de NEF, denominada NEF embutido, que se apresenta totalmente imerso nos tecidos do órgão no qual ocorre, sendo esse o padrão observado em Hymenaea stigonocarpa Mart. ex Hayne.

$\mathrm{O}$ fato dos tecidos vasculares entrarem em contato com a endoderme, extinguindo-se nessa camada, é interpretado como indício da participação dessa na transferência de materiais para o tecido secretor do NEF. Em NEFs de Acacia spp., Boughton (1981) descreve a presença de uma camada de células lignificadas que envolve o tecido secretor, na qual terminam os elementos vasculares. Nesse mesmo grupo, Zimmermann (1932) já havia descrito camada semelhante.

A endoderme apresenta células justapostas com paredes celulares impregnadas por suberina e lignina, impedindo o refluxo de néctar para o mesofilo e direcionando sua liberação para o meio externo. A ação da endoderme impedindo o movimento apoplástico e o conseqüente refluxo da secreção é reportada para diversas estruturas secretoras (Lüttge 1971; Fahn 1988; McDade \& Turner 1997; Owen \& Lennon 1999; Fahn 2000).

Nos NEFs não funcionais, a observação de fungos limitados ao tecido secretor, aliada a maior impregnação de lignina na endoderme nos permite inferir que essa 
camada impede ou dificulta a dispersão de microorganismos para os tecidos vivos do mesofilo. Segundo Van Fleet (1961), as células endodérmicas apresentam substâncias antibióticas no citoplasma, vacúolo e parede, atuando como barreira à entrada de patógenos. A proteção contra a entrada e crescimento de patógenos, pela endoderme, é relatada por Taiz \& Zeiger (1998) e Schreiber et al. (1999).

Segundo Schreiber et al. (1999), a estabilização mecânica é uma das funções da endoderme. Este fato deve ser considerado no caso dos NEFs de H. stigonocarpa pois, sobretudo após a degradação do tecido secretor, a endoderme parece atuar impedindo o colapso da região do NEF.

A presença de cristais de oxalato de cálcio nas imediações dos NEFs, como observada em Hymenaea stigonocarpa Mart. ex Hayne, é reportada por Metcalfe \& Chalk (1979), como sendo freqüente em diversos grupos taxonômicos. Relatos semelhantes são feitos por Schnell et al. (1963); Elias et al. (1975); Baker et al. (1978); Boughton (1981); Durkee (1982); Paiva et al. (2001). Segundo Paiva \& Machado (2005), a presença destes cristais pode estar relacionada à eliminação do excesso de cálcio citossólico, comum no floema e imediações de tecidos secretores.

O afastamento de células epidérmicas no pólo secretor, assim como o aspecto laxo do tecido secretor subjacente, permite a formação de canais para a passagem do néctar. A formação de espaços entre células epidérmicas da face secretora de nectários foi, também, observada por Marginson et al. (1985).

A presença de compostos lipídicos nos espaços intercelulares nos permite inferir que trata-se de componentes da secreção, o que é reforçado pelo fato de estarem nas imediações do pólo secretor e no espaço subcuticular. A observação destes compostos em maior quantidade no início da fase secretora, mostra que a planta oferece recompensa em uma forma mais energética no momento de maior suscetibilidade ao ataque de herbívoros, ou seja, quando as folhas estão em processo de expansão e diferenciação. A presença de lipídios na composição do néctar é comum e citada para nectários de diversas espécies (Baker et al. 1978; Fahn 1979; 1988; 2000; Stpiczynska et al. 2005).

Origem - Assim como observado em Hymenaea stigonocarpa Mart. ex Hayne, muitos nectários, ou porções destes, têm origem na protoderme ou em camadas subjacentes (Durkee 1982; McDade \& Turner 1997), sendo este um padrão relativamente comum de desenvolvimento destas estruturas. A participação da protoderme na formação de estruturas secretoras tem sido relatada também para estruturas secretoras internas, tais como cavidades secretoras (Solereder 1908; Turner 1986), tal fato foi registrado também para as cavidades secretoras de resina que ocorrem nas folhas de Hymenaea stigonocarpa Mart. ex Hayne (Paiva \& Machado 2006).

$\mathrm{O}$ fato da camada de células que limita o tecido secretor ser originada a partir do meristema fundamental e estabelecer limite entre este e o sistema vascular, nos permite classificá-la como endoderme, considerando-se o conceito de endoderme adotado por Fahn (1990). Segundo Van Fleet (1961), são várias as formas de endoderme e a limitação do emprego deste termo aos casos onde há estrias de Caspary e paredes suberizadas é ilogicamente restritiva. A presença de camada semelhante a endoderme, atuando como barreira ao transporte apoplástico, é comum em glândulas de secreção externa (Lüttge 1971; McDade \& Turner 1997). Entretanto, em muitos casos essa camada tem origem na protoderme sendo, então, descrita como camada intermediária (McDade \& Turner 1997).

O envolvimento do procâmbio na formação dos NEFs, como em Hymenaea stigonocarpa Mart. ex Hayne, confere a esta estrutura maior aporte de tecidos vasculares, sendo este um fato comum em NEFs vascularizados (Elias 1983).

Aspectos ultra-estruturais - A ausência de estômatos no pólo secretor, como observado nos NEFs de Hymenaea stigonocarpa Mart. ex Hayne, é característica usual em NEFs (Metcalfe \& Chalk 1979) havendo relatos semelhantes em NEFs de outras Fabaceae (Marginson et al. 1985; Paiva et al. 2001).

Observações ao MEV mostram rupturas na cutícula, no pólo secretor. Outra evidência de que a secreção é liberada por meio de rupturas na cutícula é a presença de espaços intercelulares na epiderme e a formação da câmara subcuticular. A liberação de néctar por meio de rupturas cuticulares foi também observada por Durkee (1982) e Paiva et al. (2001), em nectários extraflorais do tipo "embedded" (Elias 1983).

As características das células secretoras presentes nos NEFs de Hymenaea stigonocarpa Mart. ex Hayne, tais como núcleo volumoso, citoplasma denso, abundância de retículo endoplasmático, dictiossomos ativos, mitocôndrias, dentre outras, são relatadas para diversos nectários e indicativas de alta atividade metabólica (Fahn 1979; Durkee 1983; Fahn 1988; Stpiczynska et al. 2005). Para Lüttge (1971), o pequeno desenvolvimento do vacuoma está relacionado ao intenso metabolismo destas células. 
A presença de corpos paramurais nas células onde ocorre a dissolução da lamela mediana, e conseqüente formação de espaços para a circulação da secreção, nos permite inferir que estas estruturas atuem nesta dissolução parcial de parede. Segundo Fahn (1979) os corpos paramurais podem ser originários das vesículas dos dictiossomos e estarem relacionados à dissolução enzimática da lamela mediana. Para Marchant \& Robards (1968), os corpos paramurais podem estar envolvidos na incorporação de enzimas para sínteses extracelulares.

O retículo endoplasmático liso está presente, em grande quantidade, desde a fase inicial da atividade secretora. A abundância de retículo endoplasmático em células secretoras de néctar é citada por diferentes autores (Fahn 1988) sendo, segundo Durkee (1983), uma das mais marcantes características das células secretoras em atividade. A presença de retículo endoplasmático rugoso (RER) é mais restrita e o predomínio de retículo liso parece estar associado ao metabolismo de lipídios, bem como o transporte de precursores do néctar, como ocorre em diversas estruturas secretoras destes compostos (Fahn 1988; 2000; Stpiczynska et al. 2005).

\section{Agradecimentos}

À FAPESP, pelo apoio financeiro ao desenvolvimento deste trabalho (2001/00345-0 e Programa Biota 00/12469-3); à equipe técnica do Centro de Microscopia Eletrônica, Instituto de Biociências, Unesp, Campus de Botucatu, pelo auxílio no preparo das amostras. S.R. Machado recebe bolsa de produtividade em pesquisa do Conselho Nacional de Desenvolvimento Científico e Tecnológico - CNPq.

\section{Referências bibliográficas}

Baker, D.A.; Hall, J.L. \& Thorpe, J.R. 1978. A study of the extrafloral nectaries of Ricinus communis. New Phytologist 81: 129-137.

Blüthgen, N. \& Reifenrath, K. 2003. Extrafloral nectaries in an Australian rainforest: structure and distribution. Australian Journal of Botany 51: 515-527.

Boughton, V.H. 1981. Extrafloral nectaries of some phyllodineous Acacias. Australian Journal of Botany 29: 653-664.

Camargo, P.N. 1960. Contribuição para o conhecimento da anatomia de Hymenaea stilbocarpa Hayne. Boletim da Faculdade de Filosofia, Ciências e Letras da Universidade de São Paulo - Botânica 17(247): 11-105.
Durkee, L.T. 1982. The floral and extrafloral nectaries of Passiflora. II - The extrafloral nectary. Americam Journal of Botany 69(9): 1420-1428.

Durkee, L.T. 1983. The ultrastructure of floral and extrafloral nectaries. Pp. 1-29. In: B. Bentley \& T. Elias (eds.). The Biology of nectaries. New York, Columbia University Press.

Elias, T.S. 1972. Morphology and anatomy of foliar nectaries of Pithecellobium macradenium (Leguminosae). Botanical Gazette 133(1): 38-42.

Elias, T.S. 1980. Foliar nectaries of unusual structure in Leonardoxa africana (Leguminosae), an african obligate myrmecophyte. American Journal of Botany 67(3): 423-425.

Elias, T.S. 1983. Extrafloral nectaries: their structure and distribution. Pp. 174-203. In: B. Bentley \& T. Elias (eds.). The biology of nectaries. New York, Columbia University Press.

Elias, T.S.; Rozich, W.R. \& Newcombe, L. 1975. The foliar and floral nectaries of Turnera ulmifolia. American Journal of Botany 62(6): 570-576.

Fahn, A. 1979. Secretory tissues in plants. New York, Academic Press.

Fahn, A. 1988. Secretory tissues in vascular plants. New Phytologist 108: 229-257.

Fahn, A. 1990. Plant anatomy. 4a ed. New York, Pergamon Press.

Fahn, A. 2000. Structure and function of secretory cells. Advances in Botanical Research 31: 37-75.

Johansen, D.A. 1940. Plant microtechnique. New York, McGraw-Hill Book Co.

Karnovsky, M.J. 1965. A formaldehyde-glutaraldehyde fixative of light osmolality for use in eletron microscopy. Journal of Cell Biology 27: 137A-138A.

Koptur, S. 1992. Extrafloral nectary-mediated interactions between insects and plants. Pp. 81-129. In: E. Bernays, (ed.). Insect-Plant Interactions. Boca raton, CRC Press.

Koptur, S.; Rico-Gray, V. \& Palacios-Rio, M. 1998. Ant protection of the nectaried fern Polypodium plebeium in Central México. American Journal of Botany 85(5): 736-739.

Lee, Y.T. \& Langenheim, J.H. 1975. A systematic revision of the genus Hymenaea (Leguminosae; Caesalpinioideae; Detarieae). University of California Publications in Botany 69: 1-109.

Lüttge, U. 1971. Structure and function of plant glands. Annual Review of Plant Physiology 22: 23-44.

Marchant, R. \& Robards, A.W. 1968. Membrane systems associated with the plasmalemma of plant cells. Annals of Botany 32: 457-471.

Marginson, R.; Sedgley, M. \& Knox, R.B. 1985. Structure and histochemistry of the extrafloral nectary of Acacia terminalis (Salisb.) MacBride (Leguminosae, Mimosoideae). Protoplasma 127: 21-30.

Mazia, D.; Brewer, P.A. \& Alfert, M. 1953. The cytochemistry staining and measurement of protein with mercuric bromophenol blue. Biological Bulletin 104: 57-67. 
McDade, L.A. \& Turner, M.D. 1997. Structure and development of bracteal nectary glands in Aphelandra (Acanthaceae). American Journal of Botany 84(1): $1-15$.

Metcalfe, C.R. \& Chalk, L. 1979. Anatomy of the dicotyledons. v.1, $2^{\text {nd }}$ ed. New York, Oxford University Press.

Morellato, L.P.C. \& Oliveira, P.S. 1994. Extrafloral nectaries in the tropical tree Guarea macrophylla (Meliaceae). Canadian Journal of Botany 72: 157-160.

O’Brien, T.P.; Feder, N. \& McCully, M.E. 1964. Polychromatic staining of plant cell walls by toluidine blue. Protoplasma 59(2): 368-373.

Oliveira, P.S. \& Leitão Filho, H.F. 1987. Extrafloral nectaries: their taxonomic distribution and abundance in the woody flora of cerrado vegetation in southeast Brazil. Biotropica 19(2): 140-148.

Oliveira, P.S. \& Pie, M.R. 1998. Interaction between ants and plants bearing extrafloral nectaries in cerrado vegetation. Anais da Sociedade Entomológica do Brasil 27(2): 161-176.

Oliveira, P.S.; Klitzke, C. \& Vieira, E. 1995. The ant fauna associated with the extrafloral nectaries of Oureatea hexasperma (Ochnaceae) in an area of cerrado vegetation in central Brazil. Entomologist's Monthly Magazine 131: 77-82. 1995.

Oliveira, P.S.; Rico-Gray, V.; Díaz Castelazo, C. \& CastilloGuevara, C. 1999. Interactions between ants, extrafloral nectaries and insects herbivores in neotropical coastal sand dunes: herbivore deterrence by visiting ants increases fruit set in Opuntia stricta (Cactaceae). Functional Ecology 13: 623-631.

Oliveira, P.S. \& Freitas, A.V.L. 2004. Ant-plant-herbivore interactions in the neotropical cerrado savanna. Naturwissenschaften 91(12): 557-570.

Owen Jr., T.P. \& Lennon, K.A. 1999. Structure and development of the pitchers from the carnivorous plant Nepenthes alata (Nepenthaceae). American Journal of Botany 86(10): 1382-1390.

Paiva, E.A.S.; Morais, H.C.; Isaias R.M.S.; Rocha, D.M.S. \& Oliveira, P.E. 2001. Occurence and structure of extrafloral nectaries in Pterodon pubescens Benth. and Pterodon polygalaeflorus Benth. (FabaceaePapilionoideae). Pesquisa Agropecuária Brasileira 36(2): 219-224.

Paiva, E.A.S. \& Machado, S.R. 2005. Role of intermediary cells in Peltodon radicans (Lamiaceae) in the transfer of calcium and formation of calcium oxalate crystals. Brazilian Archives of Biology and Technology 48(1): 147-153.
Paiva, E.A.S. \& Machado, S.R. 2006. Structural and ultrastructural aspects of ontogenesis and differentiation of resin secretory cavities in Hymenaea stigonocarpa (Fabaceae-Caesalpinioideae) leaves. Nordic Journal of Botany, in press.

Pearse, A.G.E. 1980. Histochemistry theoretical and applied. Vol. II, $4^{\text {th }}$ ed. London, Longman Press.

Robards, A.W. 1978. An introduction to techniques for scanning electron microscopy of plant cells. In: Electron Microscopy and Cytochemistry of Plant Cells. J.L. Hall (eds.). New York, Elsevier.

Roland, A.M. 1978. General preparations and staining of thin sections. In: Electron Microscopy and Cytochemistry of Plant Cells. J.L. Hall (eds.). New York, Elsevier.

Sass, J.E. 1951. Botanical Microtechnique. $2^{\text {nd }}$ ed. Ames, Iowa State College Press.

Schnell, R.; Cusset, G. \& Quenum, M. 1963. Contribution a l'étude des glandes extra-florales chez quelques groupes de plantes tropicales. Revue Générale de Botanique 70(828): 269-341.

Schreiber, L.; Hartmann, K.; Skrabs, M. \& Zeier, J. 1999. Apoplastic barriers in roots: chemical composition of endodermal and hypodermal cell walls. Journal of Experimental Botany 50(337): 1267-1280.

Seago Jr., J.L.; Peterson, C.A.; Kinsley, L.J. \& Broderick, J. 2000. Development and structure of the root cortex in Caltha palustris L. and Nymphaea odorata Ait. Annals of Botany 86: 631-640.

Solereder, H. 1908. Systematic anatomy of the dicotiledons. v. I. Oxford, Clarendon Press.

Stephenson, A.G. 1982. The role of the extrafloral nectaries of Catalpa speciosa in limiting herbivory and increasing fruit production. Ecology 63(3): 663-669.

Stpiczynska, M.; Davies, K.L. \& Gregg, A. 2005. Comparative account of nectary structure in Hexisea imbricate (lindl.) Rchb.f. (Orchidaceae). Annals of Botany 95: 749-756.

Taiz, L. \& Zeiger, E. 1998. Plant physiology. $2^{\text {nd }}$ ed. Sunderland, Sinauer Associates.

Turner, G.W. 1986. Comparative development of secretory cavities in the tribes Amorpheae and Psoraleeae (Leguminosae: Papilionoideae). American Journal of Botany 73(8): 1178-1192.

Van Fleet, D.S. 1961. Histochemistry and function of the endodermis. The Botanical Review 27(2): 165-220.

Vesprini, J.L.; Galetto L. \& Bernardello, G. 2003. The benefical effect of ants on the reproductive success of Dyckia floribunda (Bromeliaceae) an extrafloral nectary plant. Canadian Journal of Botany 81(1): 24-27.

Zimmermann, J.G. 1932. Über die extrafloralen nektarien der angiospermen. Beihefte Botanisches Zentralblatt, Abt A 49: 99-196. 